\title{
Echocardiographic evaluation of left-to-right shunt in ventricular septal defect and persistent ductus arteriosus ${ }^{1}$
}

\author{
KENNETH R. BLOOM, LYDIA RODRIGUES, AND ELINOR M. SWAN \\ From the Department of Paediatrics, Division of Cardiology and Department of Biostatistics, \\ The Hospital for Sick Children, Toronto, Ontario, Canada
}

\begin{abstract}
Forty-five patients with either a ventricular septal defect or a persistent ductus arteriosus were assessed by echocardiography and cardiac catheterisation. Left atrial dimension was expressed either as a function of the body surface area ( $L A D \mathrm{~cm}$ per $m^{2} B S A$ ), or as a multiple of the aortic root dimension ( $\left.L A D / A R\right)$, and was compared with the shunt size as determined by oximetry. A highly significant $(P<0.001)$ regression relation was found for the group as a whole. A significant relation also existed for each individual group: ventricular septal defect, ventricular septal defect with pulmonary hypertension, and persistent ductus arteriosus. Regression equations were derived for the whole group. The value of echocardiography is in separating large from small shunts and in adding a dimension to the follow-up of the individual patient.
\end{abstract}

The measurement of the size of left-to-right shunts at either ventricular or aortopulmonary level has traditionally depended on the use of oxygen saturations or of an indicator such as indocyanine green, at cardiac catheterisation. More recently, the use of radionuclide angiography with injection of tracer into a peripheral vein has been shown to give comparable results (Maltz and Treves, 1973; Alderson et al., 1975).

In ventricular septal defect and in persistent ductus arteriosus an increased amount of blood is returned to the left atrium. Changes in volume of this chamber have been shown to occur in various haemodynamic disorders (Hawley et al., 1966). Echocardiography has proved itself as a noninvasive method for determination of left atrial size with a high degree of accuracy. Measurements correlate closely with those obtained by angiography (Hirata et al., 1969; Lundström and Mortensson, 1974; Ten Cate et al., 1974; Yabek et al., 1976). The larger the left-to-right shunt, the greater the volume of blood delivered to the left atrium. We designed this study to determine whether there is a relation between the magnitude of the shunt and left atrial size determined echocardiographically.

\section{Subjects and methods}

All children undergoing diagnostic cardiac catheteri-

'Supported by a grant from the Ontario Heart Foundation. Received for publication 23 June 1976 sation at The Hospital For Sick Children, Toronto, with a presumptive diagnosis of either ventricular septal defect or persistent ductus arteriosus were studied by echocardiography during the 24 hours preceding catheterisation. Forty-five patients were investigated, including 35 with ventricular septal defect and 10 with persistent ductus arteriosus. The haemodynamic and echocardiographic measurements are shown in Tables 1 and 2, respectively. Twelve of the patients with ventricular septal defect had pulmonary arterial systolic pressures greater than $\mathbf{4 0} \mathrm{mmHg}$.

\section{CATHETERISATION METHODS}

The size of the left-to-right shunt was determined by oximetry, using a Waters oximeter, and was expressed as pulmonary/systemic flow ratio. Oxygen consumption was assumed, using the tables of Lafarge and Miettinen (1970). The superior vena caval oxygen saturation was used for the mixed venous value, two samples usually being obtained from this site. All saturations were obtained consecutively, with the patient in a steady state. Any patient with angiographic and/or oximetric evidence of a significant left-to-right shunt at atrial level was excluded from the study.

\section{ECHOCARDIOGRAPHIC METHODS}

Commercially available ultrasonoscopes (Ekoline 20 or Hoffrell 101) were interfaced to a Cambridge Recorder. A variety of ultrasound transducers 
varying in frequency from $5 \mathrm{MHz}(0.25$ inch unfocused) to $2.25 \mathrm{MHz}(0.5$ inch focused at $5 \mathrm{~cm})$ were used. The mitral valve echo was identified and a sweep then made by rotating the transducer superiorly and medially until the aortic root and left atrial wall were identified (Fig. 1). Only those patients in whom these structures were clearly shown were included in the study. Measurements were made as described by Brown et al. (1974). The left atrial dimension was measured at end-systole from the anterior edge of the posterior left atrial wall to the anterior edge of the posterior wall of the aortic

Table 1 Haemodynamic and echocardiographic data in patients with ventricular septal defect

\begin{tabular}{|c|c|c|c|c|c|c|c|c|c|}
\hline $\begin{array}{l}\text { Case } \\
\text { No. }\end{array}$ & $\begin{array}{l}\text { Age at time } \\
\text { of study }\end{array}$ & $\begin{array}{l}\text { Aortic } \\
\text { pressure } \\
\text { (mmHg) } \\
\text { (mean) }\end{array}$ & $\begin{array}{l}L V \text { pressure } \\
(\mathrm{mmHg})\end{array}$ & $\begin{array}{l}\text { MPA } \\
\text { pressure } \\
\text { (mmHg) } \\
\text { (mean) }\end{array}$ & $\begin{array}{l}R V \text { pressure } \\
(\mathrm{mm} H g)\end{array}$ & $\begin{array}{l}\text { LA mean } \\
\text { pressure } \\
(\text { mm } H g)\end{array}$ & $\begin{array}{l}\text { Pulmonary/ } \\
\text { systemic flow } \\
\text { ratio }\end{array}$ & $\begin{array}{l}L A \text { dimension } \\
\text { (cm per } m^{2} \\
B S A)\end{array}$ & $L A D / A R$ \\
\hline $\begin{array}{r}1 \\
2 \\
3 \\
4 \\
5 \\
6 \\
7 \\
8 \\
9 \\
10 \\
11 \\
12 \\
13 \\
14 \\
15 \\
16 \\
17 \\
18 \\
19 \\
20 \\
21 \\
22 \\
23 \\
24 \\
25 \\
26 \\
27 \\
28 \\
29 \\
30 \\
31 \\
32 \\
33 \\
34 \\
35\end{array}$ & $\begin{array}{l}11 \mathrm{y} \\
12 \mathrm{y} \\
7 \mathrm{~m} \\
3 \mathrm{~m} \\
2 \mathrm{y} \\
4 \mathrm{y} \\
6 \mathrm{y} \\
4 \mathrm{~m} \\
12 \mathrm{y} \\
2 \mathrm{y} \\
1 \mathrm{y} \\
1 \frac{1}{2} \mathrm{~m} \\
1 \frac{1}{2} \mathrm{y} \\
9 \mathrm{y} \\
4 \mathrm{~m} \\
4 \mathrm{~m} \\
3 \mathrm{~m} \\
4 \mathrm{~m} \\
2 \frac{1}{2} \mathrm{y} \\
2 \mathrm{y} \\
14 \mathrm{y} \\
5 \mathrm{~m} \\
1 \mathrm{y} \\
2 \frac{1}{2} \mathrm{y} \\
2 \mathrm{~m} \\
2 \mathrm{~m} \\
7 \frac{1}{2} \mathrm{y} \\
8 \mathrm{y} \\
7 \mathrm{y} \\
8 \mathrm{y} \\
3 \mathrm{y} \\
5 \mathrm{y} \\
2 \mathrm{~m} \\
10 \mathrm{y} \\
6 \mathrm{y}\end{array}$ & $\begin{array}{r}105 / 56(75) \\
108 / 78(95) \\
80 / 44(60) \\
95 / 45(70) \\
95 / 48(72) \\
116 / 63(85) \\
104 / 65(85) \\
102 / 50(80) \\
105 / 65(83) \\
100 / 65(82) \\
95 / 55(73) \\
90 / 45(60) \\
85 / 55(73) \\
90 / 65(80) \\
72 / 40(54) \\
65 / 44(55) \\
83 / 49(65) \\
92 / 58(76) \\
100 / 65(82) \\
85 / 45(62) \\
79 / 50(62) \\
95 / 52(67) \\
55 / 34(44) \\
85 / 40(60) \\
110 / 76(96) \\
105 / 70(75) \\
92 / 50(71) \\
74 / 45(67) \\
95 / 50(65) \\
109 / 75(93) \\
75 / 45(55) \\
100 / 80(30) \\
94 / 52(70)\end{array}$ & $\begin{array}{c}105 / 6 \\
118 / 7 \\
80 / 9 \\
95 / 10 \\
96 / 9 \\
- \\
104 / 15 \\
102 / 10 \\
105 / 10 \\
100 / 10 \\
95 / 10 \\
90 / 10 \\
85 / 6 \\
94 / 2 \\
90 / 8 \\
72 / 5 \\
65 / 9 \\
88 / 6 \\
92 / 1 \\
92 / 1 \\
115 / 15 \\
85 / 10 \\
- \\
95 / 5 \\
55 / 8 \\
85 / 10 \\
110 / 10 \\
105 / 10 \\
74 / 4 \\
95 / 5 \\
109 / 3 \\
75 / 10 \\
100 / 9 \\
94 / 6\end{array}$ & $\begin{array}{l}34 / 14(24) \\
20 / 7(14) \\
70 / 15(44) \\
75 / 45(60) \\
28 / 6(14) \\
25 / 8(18) \\
30 / 12(14) \\
40 / 16(30) \\
27 / 9(18) \\
30 / 10(18) \\
48 / 25(35) \\
55 / 15(30) \\
23 / 7(13) \\
20 / 7 \\
45 / 15(25) \\
40 / 10(22) \\
50 / 20(39) \\
55 / 20(33) \\
49 / 11(22) \\
18 / 8(10) \\
51 / 16(32) \\
45 / 14(28) \\
20 / 7(14) \\
26 / 7(14) \\
44 / 16(26) \\
35 / 7(18) \\
27 / 7(13) \\
105 / 60(80) \\
89 / 48(64) \\
39 / 14(28) \\
30 / 12(22) \\
75 / 32(53) \\
100 / 70(82) \\
22 / 12(16)\end{array}$ & $\begin{array}{c}34 / 2 \\
20 / 6 \\
70 / 5 \\
75 / 12 \\
40 / 0 \\
32 / 4 \\
33 / 3 \\
40 / 5 \\
35 / 10 \\
58 / 8 \\
50 / 2 \\
55 / 5 \\
23 / 3 \\
20 / 0 \\
45 / 6 \\
43 / 3 \\
50 / 5 \\
60 / 7 \\
40 / 2 \\
22 / 2 \\
52 / 8 \\
48 / 7 \\
20 / 4 \\
26 / 3 \\
44 / 3 \\
50 / 5 \\
31 / 2 \\
105 / 10 \\
89 / 3 \\
76 / 4 \\
54 / 4 \\
90 / 4 \\
75 / 5 \\
100 / 6 \\
40 / 4\end{array}$ & 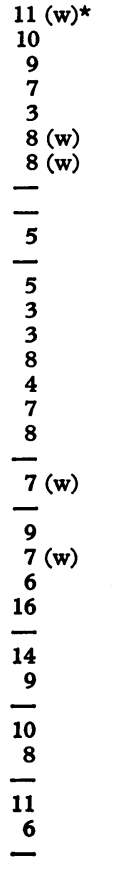 & $\begin{array}{r}1.4: 1 \\
1 \cdot 6: 1 \\
3 \cdot 8: 1 \\
2: 1 \\
2: 1 \\
1 \cdot 5: 1 \\
2: 1 \\
2 \cdot 8: 1 \\
1: 1 \\
1 \cdot 6: 1 \\
3: 1 \\
3 \cdot 4: 1 \\
1 \cdot 1: 1 \\
1 \cdot 4: 1 \\
4 \cdot 3: 1 \\
4 \cdot 2: 1 \\
5: 1 \\
5 \cdot 2: 1 \\
1 \cdot 9: 1 \\
1 \cdot 1: 1 \\
1 \cdot 5: 1 \\
2 \cdot 3: 1 \\
1 \cdot 8: 1 \\
1 \cdot 6: 1 \\
4: 1 \\
2: 1 \\
2 \cdot 2: 1 \\
1: 1 \\
0 \cdot 65: 1 \\
1 \cdot 9: 1 \\
2 \cdot 2: 1 \\
1 \cdot 3: 1 \\
3 \cdot 8: 1 \\
1 \cdot 4: 1 \\
1: 1\end{array}$ & $\begin{array}{r}3 \cdot 9 \\
2 \cdot 6 \\
10 \cdot 4 \\
9 \cdot 5 \\
7 \cdot 7 \\
5 \cdot 0 \\
4 \cdot 3 \\
6 \cdot 5 \\
2 \cdot 5 \\
4 \cdot 8 \\
6 \cdot 0 \\
7 \cdot 7 \\
7 \cdot 9 \\
2 \cdot 4 \\
6 \cdot 5 \\
6 \cdot 8 \\
9 \cdot 6 \\
13 \cdot 2 \\
4 \cdot 2 \\
2 \cdot 8 \\
3 \cdot 0 \\
7 \cdot 6 \\
4 \cdot 2 \\
4 \cdot 0 \\
9 \cdot 0 \\
11 \cdot 8 \\
3 \cdot 3 \\
2 \cdot 5 \\
2 \cdot 7 \\
2 \cdot 7 \\
6 \cdot 7 \\
3 \\
8 \cdot 3 \\
2 \cdot 8 \\
2 \cdot 6\end{array}$ & $\begin{array}{r}1 \cdot 6: 1 \\
1 \cdot 1: 1 \\
1 \cdot 9: 1 \\
1 \cdot 9: 1 \\
1 \cdot 9: 1 \\
1 \cdot 6: 1 \\
1 \cdot 6: 1 \\
1 \cdot 7: 1 \\
1 \cdot 2: 1 \\
1 \cdot 3: 1 \\
1 \cdot 5: 1 \\
1 \cdot 7: 1 \\
1 \cdot 5: 1 \\
1 \cdot 2: 1 \\
1 \cdot 4: 1 \\
1 \cdot 8: 1 \\
2: 1 \\
2 \cdot 5: 1 \\
1: 1 \\
1 \cdot 3: 1 \\
1 \cdot 6: 1 \\
2 \cdot 3: 1 \\
1: 1 \\
1 \cdot 3: 1 \\
2 \cdot 1: 1 \\
2: 1 \\
1 \cdot 8: 1 \\
1: 1 \\
1: 1 \\
1: 1 \\
1 \cdot 1: 1 \\
1: 1 \\
1 \cdot 6: 1 \\
1 \cdot 4: 1 \\
1 \cdot 3: 1\end{array}$ \\
\hline
\end{tabular}

$\star_{\mathrm{W}}=\mathrm{PA}$ wedge.

Table 2 Haemodynamic and echocardiographic data in patients with persistent ductus arteriosus

\begin{tabular}{|c|c|c|c|c|c|c|c|c|c|}
\hline $\begin{array}{l}\text { Case } \\
\text { No. }\end{array}$ & $\begin{array}{l}\text { Age at time } \\
\text { of study }\end{array}$ & $\begin{array}{l}\text { Aortic } \\
\text { pressure } \\
\text { (mmHg) } \\
\text { (mean) }\end{array}$ & $\begin{array}{l}L V \text { pressure } \\
(\operatorname{mm} H g)\end{array}$ & $\begin{array}{l}\text { MPA } \\
\text { pressure } \\
\text { (mmHg) } \\
\text { (mean) }\end{array}$ & $\begin{array}{l}R V \text { pressure } \\
(\mathrm{mmHg})\end{array}$ & $\begin{array}{l}L A \text { mean } \\
\text { pressure } \\
(\operatorname{mmHg})\end{array}$ & $\begin{array}{l}\text { Pulmonary/ } \\
\text { systemic flow } \\
\text { ratio }\end{array}$ & $\begin{array}{l}L A \text { dimension } \\
\left(\mathrm{cm} \text { per } m^{2}\right. \\
B S A)\end{array}$ & $L A D / A R$ \\
\hline $\begin{array}{r}1 \\
2 \\
3 \\
4 \\
5 \\
6 \\
7 \\
8 \\
9 \\
10\end{array}$ & $\begin{array}{l}3 \mathrm{y} \\
1 \mathrm{y} \\
4 \mathrm{y} \\
4 \mathrm{~m} \\
9 \mathrm{~d} \\
1 \mathrm{y} \\
7 \mathrm{~m} \\
4 \mathrm{y} \\
2 \mathrm{y} \\
2 \frac{1}{2} \mathrm{y}\end{array}$ & $\begin{array}{r}96 / 52(75) \\
93 / 42(65) \\
90 / 58(77) \\
85 / 40(58) \\
- \\
98 / 60(75) \\
102 / 40(70) \\
114 / 78(96) \\
101 / 56(81) \\
95 / 45(65)\end{array}$ & $\begin{array}{l}96 / 6 \\
-96 / 4 \\
-60 / 3 \\
85 / 5 \\
115 / 10 \\
- \\
95 / 5\end{array}$ & $\begin{array}{l}18 / 6(10) \\
30 / 10(20) \\
22 / 12(14) \\
21 / 10(16) \\
30 / 10 \\
25 / 8(15) \\
72 / 30(46) \\
23 / 7(14) \\
30 / 19(23) \\
35 / 10(22)\end{array}$ & $\begin{array}{l}18 / 3 \\
31 / 4 \\
22 / 2 \\
30 / 5 \\
32 / 2 \\
25 / 3 \\
72 / 6 \\
23 / 2 \\
30 / 3 \\
60 / 3\end{array}$ & $\begin{array}{l}\overline{11}(w) * \\
12 \\
-4 \\
7 \\
9 \\
2 \\
-\end{array}$ & $\begin{array}{r}1 \cdot 2: 1 \\
2 \cdot 5: 1 \\
1 \cdot 5: 1 \\
2 \cdot 7: 1 \\
2 \cdot 3: 1 \\
2 \cdot 3: 1 \\
2 \cdot 3: 1 \\
1 \cdot 2: 1 \\
3: 1 \\
1 \cdot 7: 1\end{array}$ & $\begin{array}{l}3 \cdot 9 \\
5 \cdot 4 \\
3 \cdot 6 \\
8 \cdot 3 \\
5 \cdot 7 \\
5 \cdot 6 \\
5 \cdot 9 \\
5 \cdot 9 \\
6 \cdot 4 \\
5 \cdot 6\end{array}$ & $\begin{array}{l}1 \cdot 6: 1 \\
1 \cdot 5: 1 \\
1 \cdot 5: 1 \\
2 \cdot 3: 1 \\
1 \cdot 3: 1 \\
1 \cdot 6: 1 \\
1 \cdot 9: 1 \\
1 \cdot 4: 1 \\
2 \cdot 5: 1 \\
1 \cdot 9: 1\end{array}$ \\
\hline
\end{tabular}

$\star_{\mathrm{W}}=$ PA wedge. 


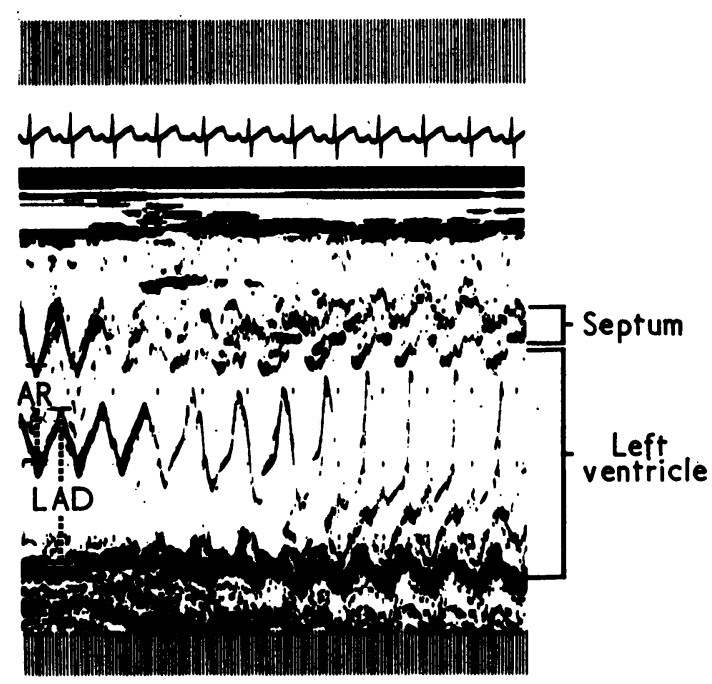

Fig. 1 Typical sweep showing method of measuring left atrial dimension ( $L A D)$ and aortic root $(A R)$ size in a patient with ventricular septal defect (pulmonary systemic flow ratio $1 \cdot 5: 1$ ).

root. The aortic root was measured at end-diastole from the anterior edge of the anterior aortic wall to the anterior edge of the posterior aortic wall. The posterior left atrial wall was identified as that echo which is continuous with the epicardial echo seen behind the left ventricular posterior wall (Fig. 1). Measurements of the left atrial dimension and aortic root were made independently by two observers: any dimension variation of greater than $1 \mathrm{~mm}$ was checked. The left atrial dimension was expressed as a function of the body surface area (LAD $\mathrm{cm}$ per $\mathrm{m}^{2} \mathrm{BSA}$ ) and as a multiple of the aortic root dimension (LAD/AR). The body surface area was determined from measurements of the height and weight using a standard nomogram (Diem and Lentner, 1970).

STATISTICAL ANALYSIS

The relation between LAD/AR or LAD and the shunt size determined by oximetry was established by linear regression. The significance of the resulting regression equation was assessed by the analysis of variance technique. These two regression relations were established and assessed for each group of patients separately and combined.

\section{Results}

The statistical analysis for all patients shows a significant relation between the left atrial dimension and the size of the left-to-right shunt $(P<0.001)$ (Fig. 2 and 3).

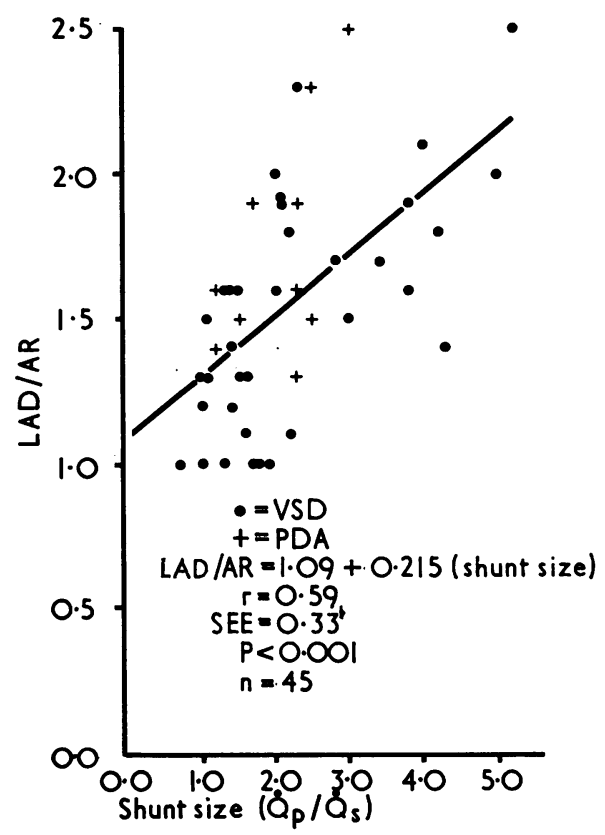

Fig. 2 Results for all patients showing the relation between $L A D / A R$ and shunt size. SEE = standard error of the estimate. Other abbreviations as in text.

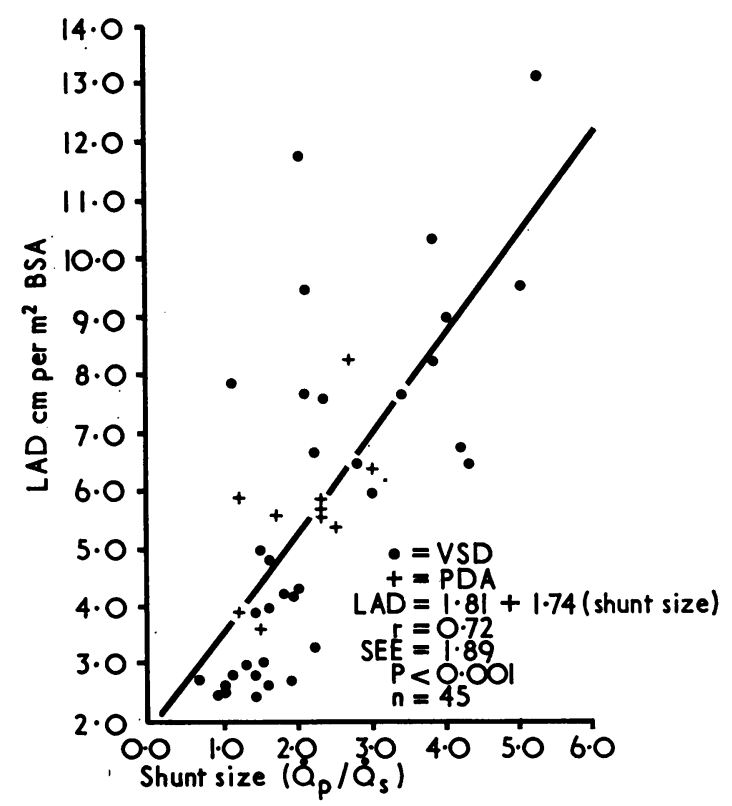

Fig. 3 Results for all patients showing the relation between left atrial dimension and shunt size. All abbreviations as before. 
Each group was then considered separately (Table 3). In all groups the LAD had a higher positive correlation with the shunt size than the LAD/AR. A particularly high correlation was found in the pulmonary hypertensive group. This group included infants with large left-to-right shunts through a ventricular septal defect as well as older children with high pulmonary vascular resistances. The high correlation in this group confirms the validity of this method of assessment of all haemodynamic types of ventricular septal defect.

The statistical correlation is lower in persistent ductus arteriosus (Table 3). The shunt in per-

Table 3 Statistical analysis

\begin{tabular}{|c|c|c|c|c|}
\hline Group & Number & $L A$ dimension & $r$ & $\begin{array}{l}\text { Significance level } \\
\text { of regression } \\
P\end{array}$ \\
\hline All patients & 45 & $\begin{array}{l}\text { LAD/AR } \\
\mathrm{LAD}^{\star}\end{array}$ & $\begin{array}{l}0.59 \\
0.72\end{array}$ & $\begin{array}{l}<0.001 \\
<0.001\end{array}$ \\
\hline $\begin{array}{l}\text { All patients with } \\
\text { VSD }\end{array}$ & 35 & $\begin{array}{l}\text { LAD/AR } \\
\text { LAD* }\end{array}$ & $\begin{array}{l}0.65 \\
0.73\end{array}$ & $\begin{array}{l}<0.001 \\
<0.001\end{array}$ \\
\hline $\begin{array}{l}\text { VSD with normal } \\
\text { pulmonary } \\
\text { artery pressure }\end{array}$ & 23 & $\begin{array}{l}\mathrm{LAD} / \mathrm{AR} \\
\mathrm{LAD} \star\end{array}$ & $\begin{array}{l}0.42 \\
0.43\end{array}$ & $\begin{array}{l}<0.05 \\
<0.005\end{array}$ \\
\hline $\begin{array}{l}\text { VSD with } \\
\text { pulmonary } \\
\text { hypertension }\end{array}$ & 12 & $\begin{array}{l}\mathrm{LAD} / \mathrm{AR} \\
\mathbf{L A D} \star\end{array}$ & $\begin{array}{l}0.78 \\
0.83\end{array}$ & $\begin{array}{l}<0.005 \\
<0.001\end{array}$ \\
\hline PDA & 10 & $\begin{array}{l}\text { LAD/AR } \\
\text { LAD* }^{\text {LA }}\end{array}$ & $\begin{array}{l}0.6 \\
0.66\end{array}$ & $\begin{array}{l}<0.10 \\
<0.05\end{array}$ \\
\hline
\end{tabular}

${ }^{\star} \mathrm{LAD}$ related to body surface area ( $\mathrm{cm}$ per $\mathrm{m}^{2} \mathrm{BSA}$ ).

sistent ductus arteriosus is distal into the pulmonary artery. It is, therefore, difficult to obtain a sample of blood that reflects adequate mixing. Streaming may result in either too high or too low oxygen saturation values being obtained by oximetry. This additional inaccuracy is the probable reason for the low correlation in this situation.

The regression equations were calculated from the data on all 45 patients, and are shown with the standard error of the estimate (SEE):

$$
\text { LAD }=1.81+1.74 \text { (shunt size). SEE } 1.89
$$

$\mathrm{LAD} / \mathrm{AR}=1.09+0.215$ (shunt size). SEE 0.33

Our results imply that a higher positive correlation will be obtained if the LAD is used rather than the LAD/AR. Problems may exist in the premature infant and newborn with the former determination; this is considered in the discussion.

\section{Discussion}

A significant relation exists between the $\mathrm{LAD} / \mathrm{AR}$ or LAD and the calculated shunt size. These correlations are low, but are similar to those found when results obtained using a dye dilution method (Bloomfield, 1974) or a radionuclide technique (Maltz and Treves, 1973) are compared with results from blood oxygen saturation data. The low correlation is probably a result of the inaccuracy of the shunt calculation from oxygen saturation data obtained by oximetry (Schostal et al., 1972). This is compounded by some inaccuracies inherent in the echocardiographic technique.

These problems in echocardiographic assessment should be considered. The left atrial dimension does not increase linearly with body surface area (Goldberg et al., 1975). Small and premature infants will have very large left atrial dimensions, if these are expressed in terms of body surface area; one should probably use the LAD/AR in this group. The use of this ratio to assess shunt size has been shown to have clinical application in premature infants (Baylen et al., 1975; Silverman et al., 1974). The left atrial dimension is affected by other factors apart from the volume of blood reaching it. Decreased left ventricular compliance will result in an increase in left atrial dimension, as will lesions of the mitral valve (Hawley et al., 1966; Yabek et al., 1976). One patient (not in this series) had a ventricular septal defect and coarctation of the aorta, and was in left ventricular failure; he had a larger left atrial dimension than expected from the size of the shunt. A coexistent atrial septal defect would result in a left atrial dimension that was smaller than expected, and patients with this associated abnormality were excluded for this reason. Other echocardiographic features of right ventricular volume overload should enable one to diagnose atrial septal defect (Meyer et al., 1972). The aortic root may be enlarged in other diseases such as Marfan's syndrome (Brown et al., 1975), and may increase in size proportionally with the shunt in persistent ductus arteriosus. A dilated root would reduce the $\mathrm{LAD} / \mathrm{AR}$. In addition, we are assessing only the anteroposterior diameter of the left atrium. This dimension is closely correlated with the volume of the left atrium in a variety of conditions (Hirata et al., 1969; Ten Cate et al., 1974). Though in a recent analysis Yabek et al. (1976), stated that 'pancaking' of the left atrium was not seen with volume overload, it is possible that distortion of this axis of the left atrium might occasionally occur.

The recognition of these problems in any individual will enhance the usefulness of the technique. This totally non-invasive method of determining the size of the left-to-right shunt could then have many clinical applications.

One of the important considerations in the clinical evaluation of a shunt is its relative rather than its absolute magnitude. Large shunts should be distinguished from small shunts. The inaccuracies of the oximetric method make this an acceptable classification. A 'grey' zone around the 2:1 dividing 
line is appreciated. Fig. 4a shows that a left atrial dimension of $5 \mathrm{~cm}$ per $\mathrm{m}^{2}$ BSA or less effectively divides small from large shunts. The one exception was an infant with clinical and radiographic evidence of a massive left-to-right shunt, who, despite the oximetric data, required immediate corrective surgery to relieve severe cardiac failure. Fig. $4 \mathrm{~b}$ shows that an $\mathrm{LAD} / \mathrm{AR}$ ratio of $1 \cdot 6: 1$ or less forms an effective dividing line between large and small shunts. Of the 3 patients who had large left-to-right shunts by oximetry but small LAD/AR, 2 had small shunts radiographically and clinically. Thus echocardiography seems to be able to define shunt size with acceptable accuracy.

Another important application of this relation between shunt size and echocardiographic left atrial dimension is in the follow-up of the individual patient. Repeated echocardiographic estimations in an individual can be made accurately. This avoids the problem of variations within a group, and also in accurate standards. Repeated observations enable the physician to add an objective measurement to his clinical assessment. This previously would have required repeated catheterisation (Hoffman and Rudolph, 1965). A decrease in the size of the left-to-right shunt as reflected by a decrease in the left atrial dimension may be the result of closure of the ventricular septal defect, the development of pulmonary hypertension, or the development of infundibular pulmonary stenosis. A raised pulmonary arterial pressure can be detected on the echocardiogram (Nanda et al., 1974; Hirschfeld et al., 1975) and likewise, infundibular stenosis (Weyman et al., 1975) and aneurysm formation (Sapire and Black, 1975) may have typical echocardiographic appearances.

Finally, another aspect of the study was the derivation of a regression equation from which shunt size can be estimated numerically. This has value in the individual, though the inaccuracies inherent in each method will be reflected in the number calculated (Kalmanson and Stegall, 1975).

A left-to-right shunt presents as a clinical composite. Echocardiography is a valuable procedure that adds to the total clinical evaluation of the situation. It does not localise the anatomical level of shunting within the ventricular septum or great arteries. Therefore, it does not supplant cardiac catheterisation in the investigation of these defects. It is, however, extremely valuable in providing an objective assessment of the magnitude of the leftto-right shunt. The need for repeated cardiac catheterisation can be avoided.

\section{References}

Alderson, P. O., Jost, R. G., Strauss, A. W., Boonvisut, S., and Markham, J. (1975). Radionuclide angiography. Circulation, 51, 1136-1143.
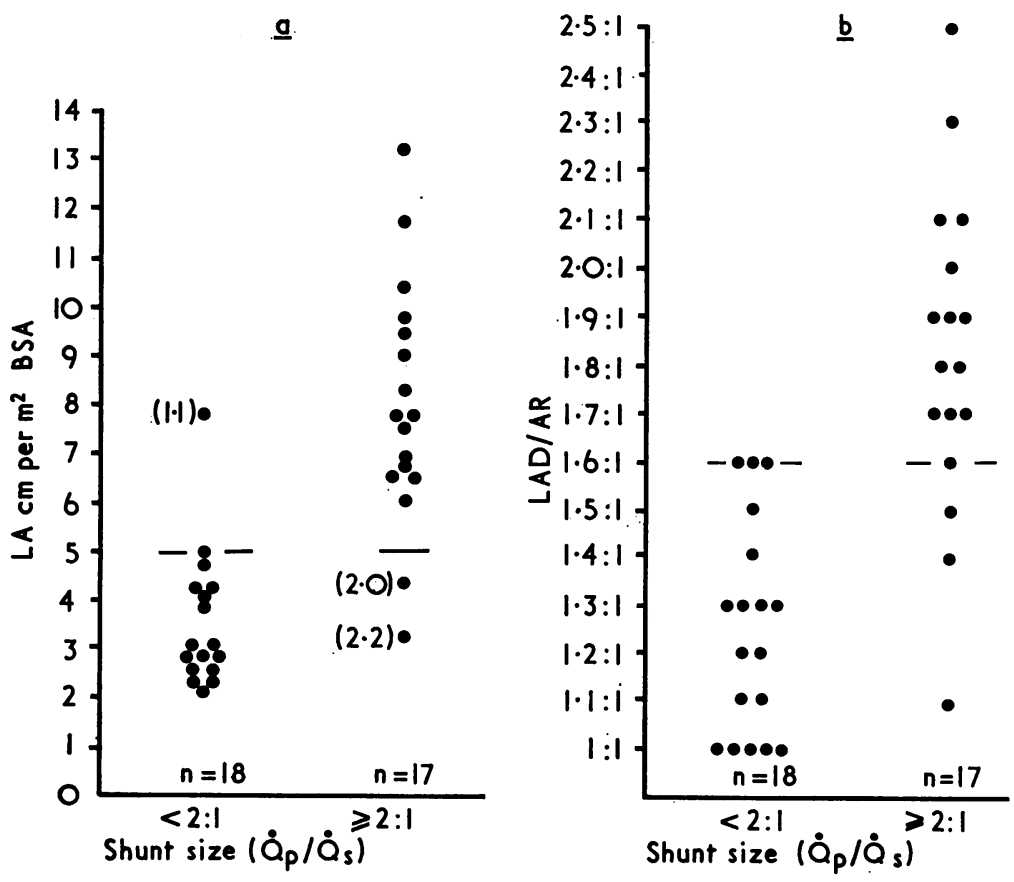

Fig. 4a and b Results for patients with $(\geqslant 2: 1)$ and small $(<2: 1)$ shunts through a ventricular septal defect. 
Baylen, B. G., Meyer, R. A., Kaplan, S., Ringenburg, W. E., and Korfhagan, J. (1975). The critically ill premature infant with patent ductus arteriosus and pulmonary disease-An echocardiographic assessment. Fournal of Pediatrics, 86, 423-432.

Bloomfield, D. A. (1974). (Ed.) Dye Curves, p. 127. University Park Press, Baltimore.

Brown, O. R., Demots, H., Kloster, F. E., Roberts, A., Menashe, V. D., and Beals, R. K. (1975). Aortic root dilatation and mitral valve prolapse in Marfan's syndrome. Circulation, 52, 651-657.

Brown, O. R., Harrison, D. C., and Popp, R. L. (1974). An improved method for echographic detection of left atrial enlargement. Circulation, 50, 58-64.

Diem, K., and Lentner, C., Ed. (1970). Scientific Tables, 7th ed., pp. 537-538. Ciba-Geigy, Basle.

Goldberg, S. J., Allen, H. D., and Sahn, D. J. (1975). Pediatric and Adolescent Echocardiography, p. 78. Year Book Medical Publishers, Chicago.

Hawley, R. R., Dodge, H. T., and Graham, T. P. (1966). Left atrial volume and its changes in heart disease. Circulation, 34, 989-996.

Hirata, T., Wolfe, S. B., Popp, R. L., Helmen, C. H., and Feigenbaum, H. (1969). Estimation of left atrial size using ultrasound. American Heart fournal, 78, 43-52.

Hirschfeld, S., Meyer, R., Schwartz, D. C., Korfhagan, J., and Kaplan, S. (1975). The echocardiographic assessment of pulmonary artery pressure and pulmonary vascular resistance. Circulation, 52, 642-650.

Hoffman, J. I. E., and Rudolph, A. M. (1965). The natural history of ventricular septal defects in infancy. American fournal of Cardiology, 16, 634-653.

Kalmanson, D., and Stegall, H. F. (1975). Cardiovascular investigations and fuzzy sets theory. American fournal of Cardiology, 35, 80-84.

Lafarge, C. G., and Miettinen, O. S. (1970). The estimation of oxygen consumption. Cardiovascular Research, 4, 23-30.

Lundström, N., and Mortensson, W. (1974). Clinical applications of echocardiography in infants and children II.
Estimation of aortic root diameter and left atrial size: a comparison between echocardiography and angiocardiography. Acta Paediatrica Scandinavica, 63, 33.

Maltz, D. L., and Treves, S. (1973). Quantitative radionuclide angiocardiography. Circulation, 47, 1049-1056.

Meyer, R. A., Schwartz, D. C., Benzing, G., III, and Kaplan, S. (1972). Ventricular septum in right ventricular volume overload. American fournal of Cardiology, 30, 349-353.

Nanda, N. C., Gramiak, R., Robinson, T. I., and Shah, P. M. (1974). Echocardiographic evaluation of pulmonary hypertension. Circulation, 50, 575-581.

Sapire, D. W., and Black, I. F. S. (1975). Echocardiographic detection of aneurysms of the interventricular septum associated with ventricular septal defect. American fournal of Cardiology, 36, 797-801.

Schostal, S. J., Krovetz, L. J., and Rowe, R. D. (1972). An analysis of errors in conventional cardiac catheterisation data. American Heart Fournal, 83, 596-603.

Silverman, N. H., Lewis, A. B., Heymann, M. A., and Rudolph, A. M. (1974). Echocardiographic assessment of ductus arteriosus shunt in premature infants. Circulation, 50, 821-825.

Ten Cate, F. J., Kloster, F. E., Van Dorp, W. G., Meester, G. T., and Roelandt, J. (1974). Dimensions and volumes of left atrium and ventricle determined by single beam echocardiography. British Heart fournal, 36, 737-746.

Weyman, A. E., Dillon, J. C., Feigenbaum, H., and Chang, S. (1975). Echocardiographic differentiation of infundibular from valvular pulmonary stenosis. American fournal of Cardiology, 36, 21-26.

Yabek, S. M., Isabel-Jones, J., Bhatt, D. R., Nakazawa, M., Marks, R. A., and Jarmakani, J. M. (1976). Echocardiographic determination of left atrial volumes in children with congenital heart disease. Circulation, 53, 268-272.

Requests for reprints to Dr. Kenneth R. Bloom, The Hospital for Sick Children, 555 University Avenue, Toronto, Ontario, Canada M5G 1X8. 